\title{
Pendidikan Seks Pada Anak Dalam Keluarga di Nagari Suayan Kecamatan Akabiluru Kabupaten Lima Puluh Kota
}

\author{
Yuliana ${ }^{1}$, Indah Muliati ${ }^{2}$ \\ yuliana290717@gmail.com¹, indahmuliati1979@gmail.com² \\ Universitas Negeri Padang ${ }^{1,2}$
}

\begin{tabular}{|c|c|}
\hline ARTIC & ABSTRACT \\
\hline Article history: & \multirow{13}{*}{$\begin{array}{l}\text { Penelitian ini dilatarbelakangi dengan adanya } \\
\text { beberapa kasus kekerasan seksual yang terjadi di } \\
\text { Nagari Suayan dalam } 2 \text { tahun terakhir. Tujuan dari } \\
\text { penelitian ini adalah untuk mendeksripsikan materi } \\
\text { pendidikan seks yang diberikan keluarga kepada anak } \\
\text { di Nagari Suayan agar anak terhindar dari kasus } \\
\text { kekerasan seksual. Jenis penelitian yang digunakan } \\
\text { adalah penelitian lapangan (field research) dengan } \\
\text { pendekatan fenomenologi. Informan dalam penelitian } \\
\text { ini dipilih secara purposive sampling yang terdiri dari } 4 \\
\text { ibu yang memiliki anak usia 0-14 tahun dan } \\
\text { pemerintahan Nagari Suayan serta instansi di } \\
\text { Kecamatan Akabiluru. Pengumpulan data dilakukan } \\
\text { melalui wawancara, observasi dan dokumentasi. Hasil } \\
\text { penelitian menunjukkan materi yang telah diberikan } \\
\text { keluarga kepada anak antara lain memberi nama } \\
\text { sesuai jenis kelamin, toilet training dan membersihkan } \\
\text { alat kelamin, menutup aurat, menstruasi, mimpi basah, } \\
\text { mandi wajib, pergaulan dengan lawan jenis dan } \\
\text { meminta izin ke kamar orang tua. }\end{array}$} \\
\hline 5 Agustus 2021 & \\
\hline Revised 24 Agustus 2021 & \\
\hline Acc & \\
\hline 202 & \\
\hline Keywords: & \\
\hline eks; anak; & \\
\hline kelu & \\
\hline & \\
\hline Clonflict of Interest: & \\
\hline None & \\
\hline Funding: & \\
\hline None & \\
\hline
\end{tabular}

Corresponding Author: Yuliana, Department Islamic Education, Faculty of Social Science, Universitas Negeri Padang, Indonesia, Email: yuliana290717@gmail.com Phone: +62821-4952-510

(c) †) Copyright@2021, Author(s)

\section{Pendahuluan}

Anak merupakan karunia yang dipercayakan oleh Allah kepada orang tua yang perlu dididik serta dibina agar tumbuh menjadi pribadi yang baik (Al-Hasan, n.d.: 6). Orang tua menjadi wahana pertama setiap anak sehingga memiliki keyakinan terhadap agama, mempelajari keterampilan dan pengetahuan, memahami nilai dan moral yang berlaku sehingga menjadi dasar anak dalam lingkungan sosialnya (Ulum, 2019: 252). Anak yang tumbuh berkembang dalam naungan syari'at Islam berdasarkan tuntunan Al Qur'an dan hadits serta perjalanan hidup para ulama Salafus 
Shalih, sehingga menjadi khazanah di dunia dan tabungan pahala di hari akhir (AlJauziyah, 2018: 2). Anak yang dididik dengan pendidikan, pergaulan, masukan, lingkungan, dan kehidupan keluarga yang baik, InsyaAllah akan menjadi manusia berjiwa terhormat serta berakhlak mulia (Al-Jauziyah, 2018).

Orang tua dan anak saat ini menghadapi tantangan yang berat karena maraknya perilaku seks bebas dan kekerasan seksual pada anak. Anak tidak hanya menjadi korban, namun juga sebagai pelaku dari kondisi tersebut. Pesatnya perkembangan teknologi, dan mudahnya akses internet, meningkatkan kerawanan menjadi objek pornografi (Kemen PPPA, 2019). Gaya berpacaran remaja semakin lama menjadi lebih berani dan terbuka (Setijaningsih, 2015) dan perilaku pacaran dapat meningkat menjadi hubungan seksual (SDKI, 2018: 125). Satu dari sebelas anak perempuan dan satu dari tujuh belas anak laki-laki Indonesia menjadi korban kekerasan seksual (SNPHAR, 2018). Pada tahun 2011-2016 terdapat 1.465 anak melakukan tindakan kekerasan seksual, sedangkan anak menjadi korban sebanyak 1.965 anak (KPAI, 2016).

Minimnya pengetahuan anak tentang seks dan sedikitnya kesadaran perilaku seks yang benar disebabkan tidak adanya bekal pendidikan atau informasi yang mereka terima dari rumah ataupun sekolah (Hasiah, 2016: 169). Rasa ingin tahu mendorong anak untuk mencari tahu sendiri dan menyebabkan kesalahan dalam menafsirkan pendidikan seks (Suminar et al., 2012). Saat ini, pendidikan seks di Indonesia belum bersifat komprehensif. Belum komprehensifnya pendidikan seks di Indonesia karena sekolah sebagai lembaga pendidikan belum memberikan materi tentang pendidikan seks kepada anak.

Salah satu ketentuan yang ada dalam Islam adalah orang tua dan guru harus melakukan upaya dan memberikan materi pendidikan seks. Hal ini penting untuk membekali anak dengan informasi yang benar sehingga mereka dapat berperilaku secara tepat (Bakhtiar \& Nurhayati, 2020: 37). Anak pada awal kehidupan memerlukan landasan yang kuat untuk tumbuh kembangnya (Nata, 2018: 203). Semua yang diperoleh anak dari keluarga dan orang terdekat, memberikan pengaruh yang signifikan untuk saat ini dan masa depannya (Nata, 2018: 203).

Penelitian ini bertujuan untuk mendeskripsikan materi pendidikan seks pada anak yang diberikan oleh keluarga di Nagari Suayan Kecamatan Akabiluru, Kabupaten Lima Puluh Kota sebagai upaya pencegahan diri anak dari maraknya perilaku seks bebas dan berbagai kekerasan seksual.

\section{Tinjauan Pustaka}

\subsection{Anak}

Anak merupakan seorang laki-laki atau perempuan dibawah usia 18 tahun yang dilahirkan dari hasil perkawinan. Hurlock (1999) membagi perkembangan anak menjadi beberapa bagian yaitu bayi (kelahiran-2 tahun), masa kanak-kanak awal (2-6 tahun), masa kanak-kanak akhir (6-12 tahun), remaja (12-18 tahun).

2.2 Pendidikan anak 
Yuliana dan Indah Muliati: Pendidikan Seks Pada Anak dalam Keluarga di Nagari Suayan...

Islam memiliki tujuan agar anak menjadi bagian masyarakat berguna bagi orang lain dan menjadi anak yang sholeh (Ulwan, 2020). Kondisi tersebut selaras dengan tujuan pendidikan nasional yaitu agar anak memiliki kekuatan rohani, keimanan, penguasaan diri, karakter, budi pekerti, keahlian, kecakapan, bagi diri sendiri, lingkungan serta negara (Undang-Undang No. 20 Tahun 2003).

\subsection{Perspektif islam tentang seksualitas}

Allah menciptakan manusia memiliki syahwat dalam rangka mempertahankan kelangsungan hidup dari kepunahan. Penggunaan nafsu syahwat harus diatur karena memiliki kecenderung melanggar aturan seperti pelecehan seksual, kekerasan seksual dan sebagainya (Nata, 2018). Islam mengatur dan membatasi naluri tersebut secara syar'i dan menyalurkannya secara benar melalui pernikahan, mengharamkan zina, dan perbuatan keji lainnya (Ismail, 2016: 37). Diantara ayat dalam Al Qur'an mengenai seksualitas yaitu QS An Nisa' : 1 tentang manusia diciptakan berpasang-pasangan, QS An Nur: 32 tentang perintah menikah dan QS. An Nuur : 31 tentang menjaga pandangan.

\subsection{Pendidikan seks}

Menurut Chomaria (2012) pendidikan seks merupakan kegiatan dimana anak akan diberikan pemahaman mengenai identitas seksual, keintiman, dan seks. Hal ini berkaitan dengan mengajarkan anatomi seksual, kesehatan reproduksi, hubungan seksual, serta mengajarkan mengenai hubungan emosi yang berkaitan dengan seksualitas individu. Pengertian lain dari pendidikan seks pada anak adalah mengajarkan pengetahuan yang berkaitan dengan seks dan pernikahan dengan cara memberikan pengertian dan keterangan yang jelas kepada anak mengenai halhal tersebut (Ulwan, 2020: 423). Berdasarkan pengertian ahli diatas dapat disimpulkan bahwa pendidikan seks merupakan memberikan pemahaman dan pengajaran serta menjelaskan mengenai informasi yang berkaitan dengan hal yang berhubungan dengan seksual, hubungan, dan keintiman ketika ia sudah memahami tentang seksual dan pernikahan.

Pendidikan seks bertujuan memberikan pengetahuan yang benar dan mendasar tentang seksualitas, dan dengan pendidikan tersebut menimbulkan kesadaran akan penjagaan diri, kemuliaan dan kesucian (Samadi, 2004). Pendidikan seks membuat anak menyadari jenis kelaminnya, sehingga anak bisa menjaga dan memelihara dirinya dan bersikap sesuai jenis kelaminnya (Chomaria, 2012).

Menurut Chomaria (2012), beberapa materi pendidikan seks yang harus diberikan pada anak yaitu :

a. Tahap awal

Perlakuan dan materi yang diberikan pada anak pada tahap ini adalah memberi nama anak sesuai jenis kelamin, mengenalkan bagian tubuh beserta fungsinya, toilet training dan membersihkan alat kelamin sendiri, memberi tahu bagian tubuh yang boleh/tidak boleh disentuh orang lain, memisahkan tempat tidur anak, membiasakan anak menutup aurat dan meminta izin di waktu-waktu tertentu.

b. Remaja 
Materi yang diberikan pada anak pada tahap ini antara lain memahamkan tentang menstruasi dan mimpi basah, pergaulan dengan lawan jenis dan mengenalkan mahram.

Ulwan (2020: 423) menjelaskan bahwa pendidikan seks penting untuk diberikan pada anak. Orang tua dan pendidik harus memberikan perhatian khusus dalam menyampaikan pendidikan ini. Berikut tingkatan pendidikan seks pada anak:

a. Tingkat awal

Kelompok umur 7-10 tahun yang disebut dengan kanak-kanak usia akhir. Materi yang diberikan tata cara minta izin dan etika melihat lawan jenis.

b. Tingkat kedua

Kelompok umur 10-14 tahun atau disebut juga remaja. Kelompok ini diarahkan untuk menghindari hal-hal yang bisa menjerumuskan pada zina.

c. Tingkat ketiga

Kelompok umur 14-16 tahun. Materi yang diberikan tentang tata cara hubungan suami istri.

d. Tingkat keempat

Pada masa ini dikenal dengan pemuda dan sudah harus bisa menjaga kehormatan dan menahan nafsu jika belum memiliki kemampuan untuk menikah.

\subsection{Permasalahan seks}

Beberapa permasalahan seks yang ditemukan antara lain perilaku pacaran dan kekerasan seksual. Menurut KBBI berpacaran adalah menjalin hubungan cinta kasih dengan lawan jenis atas dasar kasih dan sayang, tetapi tidak terikat perkawinan. Kekerasan seksual adalah setiap perlakuan yang mengandung unsur seksual oleh satu atau beberapa orang yang tidak diinginkan orang yang menjadi objek karena akan menimbulkan pengaruh yang buruk (Kemen PPPA \& Rutgers, 2018).

\section{Metode Penelitian}

Jenis penelitian yang digunakan adalah penelitian lapangan (field research) dengan pendekatan fenomenologi. Penelitian menggunakan metode kualitatif yang menghasilkan data deskriptif berupa kata-kata tertulis (Sastroasmoro, 2014: 290). Informan dalam penelitian ini dipilih secara purposive sampling yang terdiri dari $4 \mathrm{ibu}$ yang memiliki anak usia 0-14 tahun, Sekretaris Nagari Suayan, Kepala Puskesmas Batu Hampar, PKB Penyelia BPKB Kecamatan Akabiluru dan Kepala KUA Kecamatan Akabiluru. Pengumpulan data dilakukan melalui wawancara, observasi dan dokumentasi. Data dianalisis dengan model Miles dan Huberman yang dilakukan dalam 3 langkah, yaitu reduksi data, display data, serta verifikasi dan pengambilan kesimpulan. Teknik pengabsahan data yang digunakan adalah triangulasi sumber.

\section{Hasil dan Pembahasan}

Berdasarkan hasil wawancara dengan 4 subjek, terdapat 6 materi pendidikan seks yang telah diberikan orang tua kepada anaknya. Enam materi tersebut dapat terlihat di gambar berikut : 
Yuliana dan Indah Muliati: Pendidikan Seks Pada Anak dalam Keluarga di Nagari Suayan...

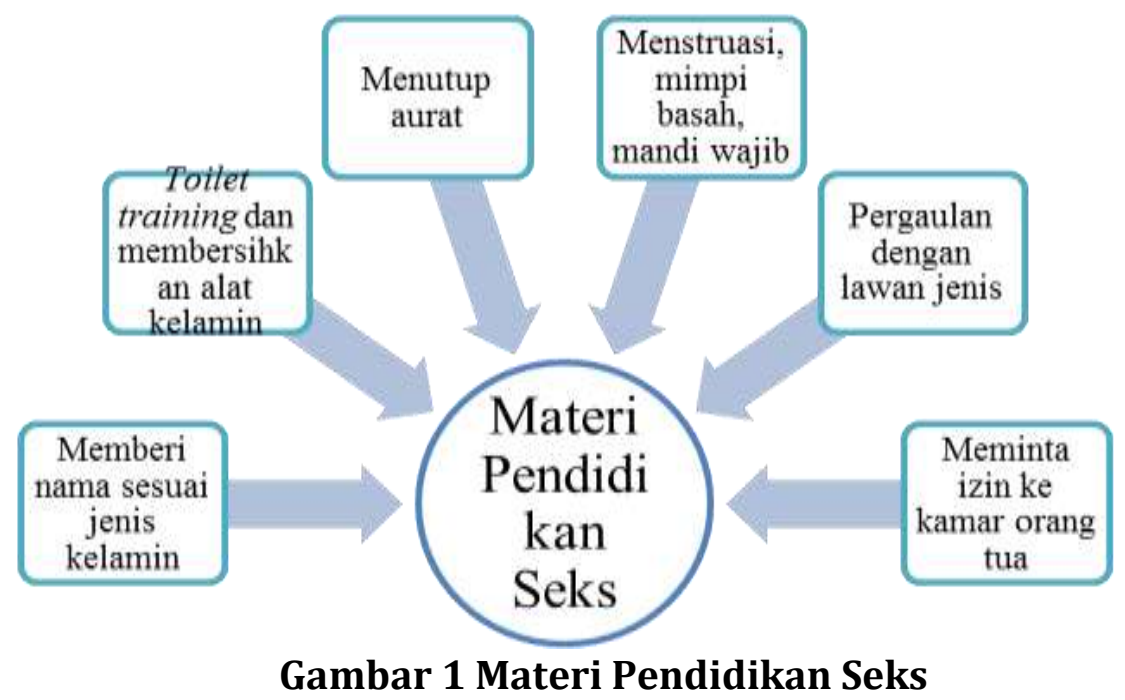

Dari gambar di atas, dapat peneliti jelaskan bahwa materi pendidikan seks yang yang telah diberikan subjek kepada anaknya adalah 1) memberi nama sesuai jenis kelamin, 2) toilet training dan membersihkan alat kelamin, 3) menutup aurat, 4) menstruasi, mimpi basah, mandi wajib, 5) pergaulan dengan lawan jenis 6) dan meminta izin ke kamar orang tua. Berikut ini peneliti akan mendeksripsikan kutipan hasil wawancara dengan subjek berdasarkan delapan materi sebagaimana yang telah dijelaskan.

Pertama yaitu memberi nama sesuai jenis kelamin. Hasil penelitian menemukan bahwa semua subjek sudah memberi nama anak mereka sesuai dengan jenis kelaminnya. Menurut Ibnu Qayyim Al-Jauziyah, ada hubungan yang erat antara nama dan yang dinamai. Dengan kata lain nama dapat berpengaruh terhadap kedamaian jiwa anak. Pemberian nama yang baik akan mendorong anak berbuat baik sesuai dengan makna namanya (Chomaria, 2012 : 20).

Kedua yaitu toilet training dan membersihkan alat kelamin. 2 (dua) orang subjek yang memiliki anak balita sudah membiasakan toilet training pada anak, namun 1 (satu) subjek belum mengajarkan anak untuk membersihkan alat kelamin sendiri dengan alasan anak masih kecil. Orang tua harus mengajarkan anak etika buang air dan cara membersihkan kelamin setelah buang hajat. Anak-anak dididik untuk mandiri dan menanamkan rasa malu sedini mungkin, sehingga anak terbiasa melindungi auratnya dari pandangan orang lain (Chomaria, 2019 : 28-29). Hasil penelitian ini sesuai dengan penelitian Artika Indah Susanti (2019) yang menemukan bahwa orang tua telah mengajarkan anaknya untuk buang air dalam kamar mandi. Materi ini dinyatakan oleh IK dan EF sebagaimana kutipan wawancara berikut:

Tabel 1 Kutipan Wawancara Materi Pertama

\begin{tabular}{lcl}
\hline Materi & Subjek & Kutipan Wawancara \\
\hline Toilet training & IK & "Tapi kalau pipis, lah bisa pipis sorang. Kalau gadang \\
dan & & iko alun diaja cebok surang lai." \\
membersihkan & & "Tapi kalau pipis sudah bisa sendiri. Kalau sebesar ini \\
alat kelamin & & belum diajari cebok sendiri." \\
\hline
\end{tabular}




EF "Ndo dibantu lai, kalau ka buang aia beko siram, nyo
lah bisa itu. Kini nyo mandi lah padian se nyo
sendirinyo.Kalau se, nenek tukang siram sajo, nyo
tukang borosiahan bitu a."
"Dia tidak dibantu lagi ke kamar mandi, kalau buang
air nanti disiram dia sudah bisa. Kalau neneknya,
nenek yang menyiram, dia (Hamdan) yang
membersihkan."

Ketiga yaitu menutup aurat. Dari hasil wawancara dan observasi dapat disimpulkan bahwa subjek yang memiliki anak perempuan belum mengajarkan anaknya menutup aurat sesuai syari'at dengan alasan anaknya masih kecil. Anakanak subjek sudah berjilbab tapi pakaiannya masih lengan pendek dan jilbab hanya digunakan ketika pergi ke tempat-tempat umum. Ada 2 orang subjek tidak memberi contoh secara langsung kepada anak dalam menutup aurat. Hal ini sesuai dengan penelitian Nhimas Ajeng Putri Aji (2018) bahwa diantara materi yang diberikan orang tua adalah mengajarkan anak berpakaian sopan.

Orang tua seharusnya tidak membiarkan anak memakai pakaian ala kadarnya dengan alasan masih kecil, karena anak-anak akan terbiasa memamerkan aurat dan tidak memiliki rasa malu. Pembiasaan lebih mudah dilakukan sedini mungkin dan hal ini untuk membentengi anak dari mata liar predator anak (Chomaria 2012: 41). Materi ini dinyatakan oleh keempat subjek sebagaimana kutipan wawancara berikut:

Tabel 2 Kutipan Wawancara Materi Kedua

\begin{tabular}{|c|c|c|}
\hline Materi & Subjek & Kutipan Wawancara \\
\hline \multirow{4}{*}{$\begin{array}{l}\text { Menutup } \\
\text { aurat }\end{array}$} & IK & $\begin{array}{l}\text { "Alun (pakai jilbab) lai." } \\
\text { "Belum (pakai jilbab)" }\end{array}$ \\
\hline & $\mathrm{EF}$ & $\begin{array}{l}\text { "Yo, bapakaian sopan sajo baajaan. Kalau anak laki-laki } \\
\text { nyo ndak apo bana do kan, ndak ditekankan bona nyo do } \\
\text { kan. Kalau lah pakaian sopannyo lah kan, ndak pakai } \\
\text { sarawa keteknyo kalua, kalau pakai sarowa hawai sajo } \\
\text { kan ndak baa do." } \\
\text { "Ya, diajarkan berpakaian sopan. Kalau anak laki-laki } \\
\text { kan tidak terlalu ditekankan. Jika sudah berpakaian } \\
\text { sopan, tidak memakai celana kecil keluar dan memakai } \\
\text { celana hawai tidak apa-apa." }\end{array}$ \\
\hline & $\mathrm{MN}$ & $\begin{array}{l}\text { "Iyo (pakai jilbab)" } \\
\text { "Iya (pakai jilbab)." }\end{array}$ \\
\hline & WR & $\begin{array}{l}\text { "Iyo, pakai jilbab. Yo, memang siko SD lah bajilbab kan, } \\
\text { jadi lah biasonyo bajilbab kan. Cuman kalau di rumah } \\
\text { ndak do, kalau di rumah-rumah sajo. Tapi kalau lah } \\
\text { kaluanyo beko pakai jilbab." } \\
\text { "Iya, pakai jilbab. Iya, karena SD sudah pakai jilbab. } \\
\text { Cuma kalau di rumah saja tidak. Kalau pergi keluar } \\
\text { pakai jilbab." }\end{array}$ \\
\hline
\end{tabular}


Yuliana dan Indah Muliati: Pendidikan Seks Pada Anak dalam Keluarga di Nagari Suayan...

Keempat yaitu menstruasi, mimpi basah dan mandi wajib. Hasil penelitian menemukan subjek yang mempunyai anak perempuan baligh, sudah mengajarkan anak-anak mereka tentang hal-hal yang berkaitan dengan menstruasi. Sedangkan subjek yang mempunyai anak laki-laki baligh, berbagi peran dengan ayah dalam menjelaskan perihal mimpi basah. Semua subjek juga sudah mengajarkan tata cara mandi wajib. Menstruasi dan mimpi basah merupakan tanda seorang anak sudah baligh dan mampu untuk untuk bereproduksi. Hal ini sesuai dengan penelitian Nurlaila Novi Istiqomah (2017) yang menunjukkan bahwa orang tua mengajarkan anaknya mengenai hal yang berkaitan dengan masa baligh dan membersihkan diri dari najis.

Orang tua seharusnya sudah mengenalkan pada anak-anak yang akan memasuki usia remaja tentang alat reproduksi dan fungsinya agar, anak bisa menghindari apa yang seharusnya tidak dilakukan serta konsekuensi perbuatannya. Ibu memiliki peran yang besar untuk mengajarkan anak perempuannya seluk-beluk menstruasi. Ada beberapa tanda-tanda anak perempuan akan mengalami menstruasi seperti tumbuhnya payudara, dan bulu di kemaluan. Ayah dapat berperan dalam menjelaskan perihal mimpi basah pada anak laki-laki seperti pertumbuhan rambut di kulit dan kemaluan, suara yang membesar, mengalami mimpi basah serta tata cara mandi wajib (Chomaria 2012: 31-33). Materi ini dinyatakan oleh subjek EF, MN dan WR sebagaimana kutipan wawancara berikut:

Tabel 3 Kutipan Wawancara Materi Ketiga

\begin{tabular}{|c|c|c|}
\hline Materi & Subjek & Kutipan Wawancara \\
\hline $\begin{array}{l}\text { Mimpi } \\
\text { basah }\end{array}$ & $\mathrm{EF}$ & $\begin{array}{l}\text { "Keceknyo tu harus ditanyoan anak wak tu. Lainyo mimpi } \\
\text { tu jo, misalnyo yang laki-laki, lainyo mimpi jo urang } \\
\text { perempuan inyo, atau sesama jenisnyo mimpi basah." } \\
\text { "Katanya anak harus ditanya. Jika dia laki-laki apakah } \\
\text { dia mimpi dengan perempuan, atau dengan sesama } \\
\text { jenis." }\end{array}$ \\
\hline \multirow[t]{2}{*}{ Menstruasi } & MN & $\begin{array}{l}\text { "Kalau men itu, sakik poruik wak. Sudah tu kalau lah men } \\
\text { tu bisa hamil. } \\
\text { "Kalau sudah men nanti sakit perut dan juga bisa hamil." }\end{array}$ \\
\hline & WR & $\begin{array}{l}\text { "Tu lah godang wak namonyo tu (kalau sudah men)." } \\
\text { "Jadi diberitahu kalau sudah men itu sudah besar." }\end{array}$ \\
\hline $\begin{array}{l}\text { Mandi } \\
\text { wajib }\end{array}$ & WR & $\begin{array}{l}\text { "Yo baajakan. Niatnyo, kok obuak jan disikek-sikek dulu, } \\
\text { kalau ruruak obuak tu simpan. Itu kecek urang dulu dulu } \\
\text { kan. Simpan dih." } \\
\text { "Diajarkan, niatnya, kalau rambut tidak boleh disisir, } \\
\text { dan kalau rambut yang rontok disimpan. Itu kata orang } \\
\text { dulu. Simpan ya." }\end{array}$ \\
\hline
\end{tabular}

Kelima yaitu pergaulan dengan lawan jenis. Semua subjek yang memiliki anakanak usia baligh sudah mengajarkan anak tentang batasan pergaulan dengan lawan jenis. Bercampurnya anak yang berlawanan jenis ketika masih kecil adalah hal lumrah karena aktifitas bersama merupakan bentuk sosialisasi anak agar saling mengenal antar satu dan yang lain. Seiring bertambahnya usia, anak harus dibiasakan tidak bercampur, menjaga sikap dan jarak dengan lawan jenis untuk mengantisipasi 
tidak terjadinya hal-hal yang buruk seperti pergaulan bebas dan pelecehan seksual (Irsyad, 2019 : 205-206). Penelitian Nurlaila Novi Istiqomah (2017) menunjukkan bahwa orang tua mengajarkan anaknya mengenai batasan pergaulan dengan lawan jenis. Materi ini dinyatakan oleh subjek MN dan WR sebagaimana kutipan wawancara berikut:

Tabel 4 Kutipan Wawancara Materi Keempat

\begin{tabular}{lcl}
\hline Materi & Subjek & Kutipan Wawancara \\
\hline Pergaulan & MN & "Ndak buliah ampiang-ampiang ka urang jantan. Lah \\
dengan & bisa poruk wak godang. Olun (pacaran) lai, yo wak ka \\
lawan jenis & sekolah, kalau bacewek-cewek tu awak copek nikah. \\
& Nomuah copek nikah?" \\
& "Jadi tidak boleh mendekat ke orang laki-laki. Belum \\
& (belum boleh pacaran), kalau pacaran nanti bisa cepat \\
& menikah. Kamu mau cepat nikah?" \\
\cline { 2 - 4 } & "Jan dokek-dokek jo anak jantan ndak. Berarti wak lah \\
& godang tu, lah remaja wak namonyo." \\
& "Diingatkan jangan dekat-dekat (mendekat) dengan \\
& laki-laki karena kita sudah remaja." \\
\hline
\end{tabular}

Keenam yaitu meminta izin ke kamar orang tua. Peneliti menemukan bahwa belum semua subjek mengajarkan anak untuk meminta izin sebelum masuk ke kamar orang tua. Anak sudah minta izin sebelum masuk ke kamar orang tua, tetapi hanya pada malam hari. Penelitian Ramadhani (2020) menunjukkan bahwa orang tua mengajarkan anaknya untuk meminta izin sebelum masuk ke kamar orang tua. Namun, hal ini tidak sesuai dengan apa yang diperintahkan oleh Allah agar anak meminta izin sebelum masuk ke kamar orang tua terutama pada 3 waktu tertentu, yaitu sebelum subuh, tengah hari dan setelah shalat isya.

Dalam QS An Nuur ayat 58-59 Allah memerintahkan anak-anak untuk meminta izin sebelum masuk ke kamar orang tua pada 3 waktu tersebut karena merupakan waktu istirahat bagi orang tua. Selain itu, orang tua biasanya menggunakan waktu tersebut untuk aktivitas yang sangat privasi, dimana aurat (segala sesuatu yang dapat menjadikan malu) yang belum pantas dilihat oleh anak kemungkinan akan terbuka. Oleh karena itu anak harus dibiasakan untuk meminta izin sebelum masuk ke kamar orang tua (Irsyad, 2019 : 176). Materi ini dinyatakan oleh subjek MN sebagaimana kutipan wawancara berikut:

Tabel 5 Kutipan Wawancara Materi Kelima

\begin{tabular}{lcl}
\hline Materi & Subjek & Kutipan Wawancara \\
\hline $\begin{array}{l}\text { Meminta } \\
\text { izin ke }\end{array}$ & MN & $\begin{array}{l}\text { "Iyo, kalau malam, kalau siang ndo nyo mintak izin (ke } \\
\text { kamar orang tua)" } \\
\text { kamar }\end{array}$ \\
orang tua & $\begin{array}{l}\text { "Iya, kalau malam, kalau siang tidak mintak izin (ke } \\
\text { kamar orang tua). }\end{array}$ \\
\hline
\end{tabular}

Dalam penelitian ini, peneliti juga mewawancarai pemerintahan Nagari Suayan dan instansi di Kecamatan Akabiluru untuk mengetahui materi pendidikan 
Yuliana dan Indah Muliati: Pendidikan Seks Pada Anak dalam Keluarga di Nagari Suayan...

seks yang telah diberikan kepada masyarakat. Ada beberapa materi yang telah diberikan oleh pemerintah daerah kepada masyarakat secara perorangan dan kelompok antara lain :

\section{Tabel 6 Kutipan Wawancara Materi}

\begin{tabular}{cl}
\hline Subjek & Kutipan Wawancara \\
\hline RS & "Kemudian untuk remaja, tentu itu sudah jelas, bagaimana, secara fisik \\
& ya, mereka harus mengenal bagaimana proses kehamilam segala macam \\
& itu kan. Itu yang diberikan untuk remaja. Kemudian di skrining calon \\
& pengantin, sebenarnya lebih kepada bagaimana mereka menyiapkan diri \\
& untuk mejalani rumah tangga gitu kan, kemudian untuk penyuluhan \\
& untuk kelompok-kelompok resti biasanya lebih kepada edukasi, dan ini \\
& biasanya mengundang narasumber, narasumber dari psikolog kan, lebih \\
& kepada persiapan orang tua mendidik anak agar tidak terjerumus ke \\
& jalan yang salah." \\
"Yo pengenalan alat kontrasepsi, tu tentang 8 fungsi keluarga, ado kan \\
istilahnyo 4 terlalu. Terlalu kan terlalu muda melahirkan, tu terlalu sering \\
melahirkan, terlalu tua untuk melahirkan, terlalu muda untuk \\
melahirkan, terlalu banyak. Tu a, 4 terlalu kan. Dikecekkan waktu di catin \\
tu.Kalau materi di sekolah ko tentang kesehatan reproduksi." \\
"Ya pengenalan alat kontrasepsi, kemudian tentang 8 fungsi keluarga, \\
ada kan istilahnya 4 terlalu. 4 terlalu dijelaskan waktu di skrining calon \\
pengantin. Terlalu muda melahirkan, terlalu sering melahirkan, terlalu \\
tua untuk melahirkan, terlalu banyak untuk melahirkan." \\
"Pelatihan, penyuluhan lai, narkoba, nan awak adokan e." \\
"Pelatihan, penyuluhan ada, narkoba, yang kita adakan." \\
"Tentang fikih ibadahnya, kalau mamak di rumah jangan pakai celana \\
pendek, ya hal-hal yang berkaitan dengan rumah tangga dan agama."
\end{tabular}

Dari 4 informan sumber, materi yang diberikan kepada masyarakat antara lain kesehatan reproduksi, kehidupan rumah tangga, alat kontrasepsi, narkoba dan fikih ibadah. Materi yang diberikan oleh pemerintah Nagari Suayan dan instansi di Kecamatan Akabiluru bertujuan sebagai untuk menambah wawasan masyarakat tentang pendidikan seks dan upaya pencegahan terjadinya kasus kekerasan seksual. Pemerintahan nagari dan pihak terkait lainnya, agar lebih meningkatkan kegiatan pemberian edukasi kepada masyarakat dengan melibatkan berbagai tenaga ahli lainnya, seperti psikologi, ulama, serta kader remaja (GenRe).

\section{Simpulan}

Kesimpulan dari penelitian ini, diantara materi yang diberikan keluarga kepada anak yaitu memberi nama sesuai jenis kelamin, toilet training dan membersihkan alat kelamin, menutup aurat, menstruasi, mimpi basah, mandi wajib, pergaulan dengan lawan jenis dan meminta izin ke kamar orang tua. Sedangkan materi yang belum diberikan antara lain mengenalkan bagian tubuh dan fungsinya, memberi tahu bagian tubuh yang boleh/tidak boleh disentuh, menutup aurat sesuai syari'at dan tentang mahram. Diantara materi yang diberikan oleh pemerintah Nagari Suayan dan instansi di Kecamatan Akabiluru kepada masyarakat antara lain mengenai kesehatan reproduksi, kehidupan rumah tangga, alat kontrasepsi, narkoba dan fikih ibadah. 


\section{Referensi}

Aji, N. A. P. (2018). Pelaksanaan Pendidikan Seksual Pada Anak Usia Dini Oleh Orang Tua dan Guru di TK Pamekar Budi Demak. Universitas Kristen Satya Wacana.

Al-Hasan, S. Y. M. (n.d.). Pendidikan Anak Dalam Islam. Yayasan Al-Sofwa.

Al-Jauziyah, I. Q. (2018). Hanya Untukmu Anakku: Panduan Lengkap Pendidikan Anak Sejak Dalam Kandungan Hingga Dewasa. Jakarta: Pustaka Imam AsySyafi'i.

Bakhtiar, N., \& Nurhayati. (2020). Pendidikan seks bagi anak usia dini menurut hadist nabi. Jurnal Pendidikan Islam Anak Usia DIni, 3(1), 36-44.

Hasiah. (2016). Konsep Pendidikan Seks Dalam Perspektif Alquran. Forum Paedagogik, 08(02), 154-173.

Hurlock, E. B. (1999). Psikologi Perkembangan. Jakarta: Erlangga.

Ismail, J. bin A. bin. (2016). Bahaya Penyimpangan Seksual: Zina, Homoseks, Lesbi dan Lainnya. Jakarta: Darul Haq.

Istiqomah, N. N. (2017). Peran Orang Tua Dalam Pendidikan Seks Bagi Remaja Menurut Perspektif Islam. Institut Agama Islam (IAIN) Metro.

Kemen PPPA. (2019). Lindungi Anak dari Pornografi, Desa Perlu Turun Tangan. Diambil 16 Maret 2021, dari https://www.kemenpppa.go.id/index.php/page/read/29/2191/lindungianak-dari-pornografi-desa-perlu-turun-tangan

Kemen PPPA, \& Rutgers. (2018). Modul Kesehatan Reproduksi: Perlindungan Anak Terpadu Berbasis Masyarakat (PATBM). Kementerian Pemberdayaan Perempuan dan Perlindungan Anak Republik Indonesia.

KPAI. (2016). Rincian Data Kasus Berdasarkan Klaster Perlindungan Anak, 20112016. Diambil 12 Maret 2021, dari https://bankdata.kpai.go.id/tabulasi-dataperlindungan-anak

Lesmana, C. B. J. (2017). Buku Panduan Belajar Koas: Ilmu Kedokteran Jiwa. Denpasar: Udayana University Press.

Nata, A. (2018). Psikologi Pendidikan Islam. Depok: RajaGrafindo Persada.

Noeratih, S. (2016). Peran Orang Tua Terhadap Pendidikan Seks Untuk Anak Usia 4-6 Tahun (Studi Deskriptif Di Desa Wanakaya Kecamatan Gunung Jati Kabupaten Cirebon Jawa Barat). Universitas Negeri Semarang.

Ramadhani, \& Efendi. (2020). Peran Orang Tua Dalam Memberikan Pendidikan Seks Pada Anak Usia 6-13 tahun di Desa Sungai Kuyung Kecamatan Pancung Soal. Jurnal Kepemimpinan dan Kepengurusan Sekolah, 5(2), 196-201.

Sastroasmoro, S. (2014). Dasar-dasar Metodologi Penelitian Klinis (5 ed.). Jakarta: Sagung Seto.

SDKI. (2018). Survei Demografi dan Kesehatan Indonesia 2017: Buku Remaja. Jakarta: Badan Kependudukan dan Keluarga Berencana Nasional.

Setijaningsih, T. (2015). Gaya Berpacaran Remaja di Sekolah Menengah Kota Blitar. Jurnal Ners dan Kebidanan Uournal of Ners and Midwifery), 2(2), 115-119. https://doi.org/10.26699/jnk.v2i2.art.p115-119

SNPHAR. (2018). Fakta Kekerasan Terhadap Anak di Indonesia. Kementerian Pemberdayaan Perempuan dan Perlindungan Anak Republik Indonesia.

Suminar, M. C. R., Dharminto, \& Dharmawa, Y. (2012). Korelasi Sumber Informasi Media dan Lingkungan Pergaulan Dengan Perilaku Seksual Remaja Dalam 
Yuliana dan Indah Muliati: Pendidikan Seks Pada Anak dalam Keluarga di Nagari Suayan...

Berpacaran. Jurnal Kesehatan Masyarakat, 1(2), 187-205. https://doi.org/10.4135/9781412983907.n697

Susanti, A. I. (2019). Peran Orang Tua Dalam Memberikan Pendidikan Seks Sejak Dini Pada Anak Usia 5-6 Tahun di TK Aba Piyungan. UAD Yogyakarta.

Ulum, A. . S. (2019). The Prophetic Parenting. Yogyakarta: Mueeza.

Ulwan, A. N. (2020). Tarbiyatul Aulad Fil Islam : Pendidikan Anak Dalam Islam. Solo: Insan Kamil.

Undang-Undang No. 20 Tahun 2003. Undang-Undang Sistem Pendidikan Nasional (UUSPN) Nomor 20 Tahun 2002 Bab 1 Pasal 1.

UU Nomor 21 Tahun 2007. Undang-Undang Republik Indonesia Nomor 21 Tahun 2007 Tentang Tindak Pidana Perdagangan Orang. 